\title{
Polygonaceae endémicas del Perú
}

\section{Blanca León ${ }^{1,2}$}

${ }^{1}$ Museo de Historia Natural, Av. Arenales 1256, Aptdo. 14-0434, Lima 14, Perú

2 Plant Resources Center, University of Texas at Austin, Austin TX 78712 EE.UU.

blanca.leon@mail.utexas.edu

\section{Resumen}

La familia Polygonaceae es reconocida en el Perú por presentar diez géneros y 73 especies (Brako \& Zarucchi, 1993; Ulloa Ulloa et al., 2004), entre árboles, arbustos y hierbas, e incluso lianas. En este trabajo reconocemos diez endemismos en cinco géneros. El género más rico en especies es Ruprechtia. Los taxones endémicos se encuentran principalmente en la región Mesoandina, entre los 2000 y 3300 m de altitud. Se aplicaron las categorías y criterios de la UICN a cuatro especies. Aparentemente, sólo una especie se encuentra representada dentro del Sistema Nacional de Áreas Naturales Protegidas por el Estado.

Palabras claves: Polygonaceae, Ruprechtia, Perú, endemismo, plantas endémicas.

\section{Abstract}

The Polygonaceae are represented in Peru by ten genera and 73 species (Brako \& Zarucchi, 1993; Ulloa Ulloa et al., 2004), between trees, shrubs and herbs, including lianas. Here we recognize ten endemic taxa in five genera. Ruprechtia is the genus with the largest number of endemic species. Endemic taxa are found mainly in the Mesoandean region, between 2000 and 3300 m elevation. We applied IUCN categories and criteria to four species. Apparently, only one endemic species has been recorded within Peru's protected areas system.

Keywords: Polygonaceae, Ruprechtia, Peru, endemism, endemic plants.

\section{Coccoloba gracilis Kunth}

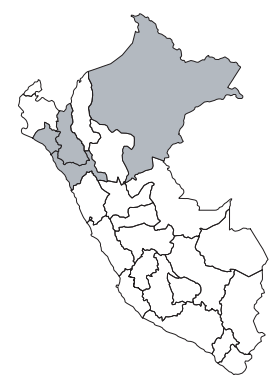

Publicación: Nov. Gen. Sp. (quarto ed.) 2: 176. [1818]. 1817.

Colección tipo: A. Humboldt s.n.

Herbarios: B.

Nombre común: Desconocido.

Registro departamental: CA, LA, LL, LO, Regiones Ecológicas: MDE, MA; 700$3300 \mathrm{~m}$.

SINANPE: Sin registro.

Herbarios peruanos: HUT (5).

Observaciones: Este taxón fue considerado por Brako \& Zarucchi (1993) como un endemismo; sin embargo, no ha sido posible evaluarlo, ni asignarle una categoría.

\section{Coccoloba nutans Kunth}

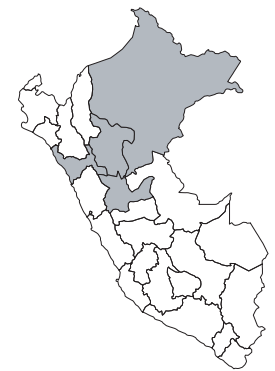

Publicación: Nov. Gen. Sp. (quarto ed.) 2: 175. [1818]. 1817.

Colección tipo: A. Humboldt s.n.

Herbarios: P.

Nombre común: Desconocido.

Registro departamental: HU, LL, LO, SM.

Regiones Ecológicas: Sin datos; altitud desconocida.

SINANPE: Sin registro.

Herbarios peruanos: Ninguno.

Observaciones: Este taxón fue considerado por Brako \& Zarucchi (1993) como un endemismo; sin embargo, no ha sido posible evaluarlo, ni asignarle una categoría.

\section{Muehlenbeckia nummularia H. Gross}

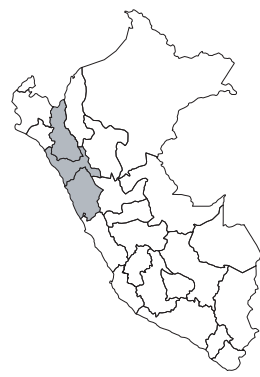

Publicación: Bot. Jahrb. Syst. 49: 346. 1913.

Colección tipo: A. Weberbauer 3172

Herbarios: B, G; MOL!

Nombre común: Desconocido.

Registro departamental: AN, CA, LL.

Regiones Ecológicas: MA; $3300 \mathrm{~m}$.

SINANPE: Sin registro.

Herbarios peruanos: HUT (2), MOL (isotipo).

Observaciones: Bejuco conocido de localidades dispersas en ambas vertientes andinas, de las cuencas del Nepeña, Marañón y Urubamba. No ha sido posible evaluarlo, ni asignarle una categoría.

\section{Polygonum peruvianum Meissn.}

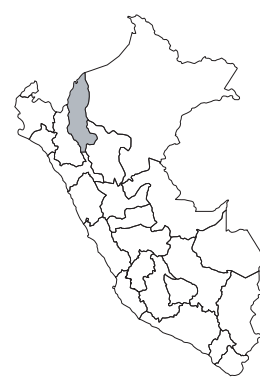

Publicación: Prodr. 14: 122. 1857.

Colección tipo: A. Mathews 3120

Herbarios:

Nombre común: Desconocido.

Registro departamental: AM.

Regiones Ecológicas: Sin datos; altitud desconocida.

SINANPE: Sin registro.

Herbarios peruanos: Ninguno.

Observaciones: Este taxón fue considerado por Brako \& Zarucchi (1993) como un endemismo; sin embargo, no ha sido posible evaluarlo, ni asignarle una categoría. 


\section{Ruprechtia albida Pendry}

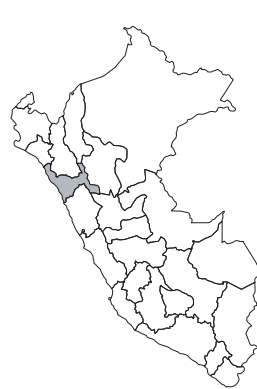

EN, B1ab(iii)

Publicación: Edinburgh J. Bot. 60(1): 35, 37-38, f. 12-13. 2003.

Colección tipo: K.R. Young 1202

Herbarios: A, F; HUT!

Nombre común: Desconocido.

Registro departamental: LL.

Regiones Ecológicas: BS; 1300—1900 m.

SINANPE: Sin registro.

Herbarios peruanos: HUT (isotipo).

Observaciones: Especie arbustiva conocida de un área pequeña, en la cuenca del Marañón. La población original ha sido parcialmente destruida por la ampliación de una carretera. Un tema de preocupación, es el hecho que no hay una parte del bosque seco, interandino, dentro del sistema de áreas protegidas.

\section{Ruprechtia aperta Pendry}

\section{DD}

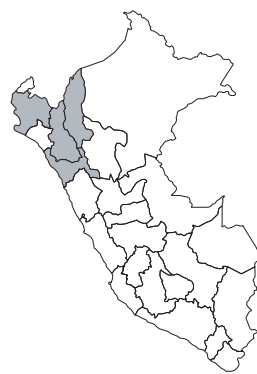

Publicación: Edinburgh J. Bot. 60(1): 4042, f. 15-16 2003.

Colección tipo: C. Díaz 2190

Herbarios: F, NY; USM!.

Nombre común: Guayabilla.

Registro departamental: AM, CA, LL, PI.

Regiones Ecológicas: MA, BS; 360—3000 $\mathrm{m}$.

SINANPE: Sin registro

Herbarios peruanos: USM (isotipo).

Observaciones: Árbol conocido de varias localidades con vegetación estacional. La localidad original, «entre Chagual y Aricapampa», erróneamente se atribuyó a Cajamarca, pero está ubicada en La Libertad. Se desconoce el estado de sus poblaciones.

\section{Ruprechtia obovata Pendry}

\section{DD}

Publicación: Edinburgh J. Bot. 60(1): 3840, f. 14-15 2003.

Colección tipo: A. Sagástegui A. et al. 15360

Herbarios: E.

Nombre común: Desconocido.

Registro departamental: CA.

Regiones Ecológicas: MDE; $2000 \mathrm{~m}$.

SINANPE: Sin registro.

Herbarios peruanos: Ninguno.

Observaciones: Árbol conocido sólo de la cuenca del Magdalena, en la vertiente del Pacífico, donde fue recolectado en 1994. Se desconoce el estado actual de sus poblaciones.

\section{Ruprechtia peruviana Pendry}

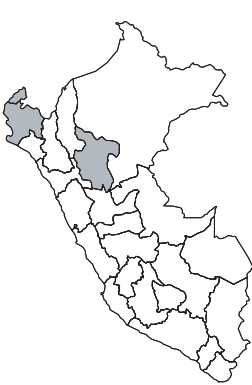

\section{VU, B1a}

Publicación: Edinburgh J. Bot. 60(1): 3435, f. 11, 132003.

Colección tipo: C. Díaz \& E. Peña 4064

Herbarios: AAU, MO.

Nombre común: Desconocido.

Registro departamental: PI, TU.

Regiones Ecológicas: DCT; $800 \mathrm{~m}$.

SINANPE: PNCAm

Herbarios peruanos: Ninguno.

Observaciones: Árbol o arbusto conocido de varios ejemplares de Piura y Tumbes, distantes entre ellos unos $25 \mathrm{~km}$, en la vertiente del Pacífico. Una población ha sido registrada en el Parque Nacional Cerros de Amotape tanto en 1987 coo en 1990. Esta especie probablemente se encuentre en Ecuador.

\section{Triplaris peruviana Fisch. \& Meyer ex C.A. Meyer}

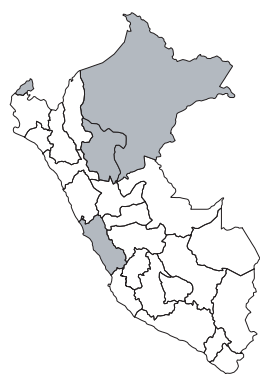

Publicación: Mem. Acad. Imp. Sci. SaintPetersbourg, Ser. 6, Sci. Math., Seconde Pt. Sci. Nat. 6(2):149. 1845.

Colección tipo: A. Mathews 1620

Herbarios: G.

Nombre común: Desconocido.

Registro departamental: LI, LO, SM, TU.

Regiones Ecológicas: DCT; altitud desconocida.

SINANPE: Sin registro.

Herbarios peruanos: MOLF (1).

Observaciones: Árbol conocido de varias localidades, mayormente, en la Amazonía peruana. No ha sido posible evaluar esta especie, ni asignarle una categoría.

\section{Triplaris setosa Rusby var. woytkowskii Brandbyge}

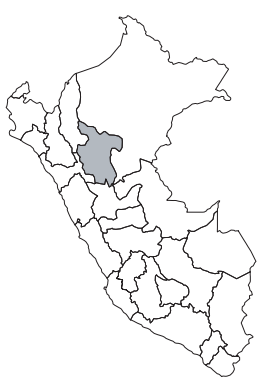

Publicación: Nordic J. Bot. 6: 561. 1986. Colección tipo: F. Woytkowski 7187

Herbarios:

Nombre común: Desconocido.

Registro departamental: SM.

Regiones Ecológicas: BMHP; 970—1200 $\mathrm{m}$.

SINANPE: Sin registro.

Herbarios peruanos: HAO (1).

Observaciones: Este taxón fue considerado por Brako \& Zarucchi (1993) como un endemismo; sin embargo, no ha sido posible evaluarlo, ni asignarle una categoría. 